\title{
Aerobic oxidation of isopropylaromatic hydrocarbons to hydroperoxides catalyzed by $N$-hydroxyphthalimide
}

\author{
Beata Orlińska · Jan Zawadiak
}

Received: 6 February 2013/Accepted: 7 May 2013/Published online: 22 May 2013

(C) The Author(s) 2013. This article is published with open access at Springerlink.com

\begin{abstract}
The oxidations of cumene, 4-isopropylbiphenyl, 1-methoxy-4-(1-methylethyl)benzene, 2-isopropylnaphthalene, 2-methoxy-6-(1-methylethyl)naphthalene, 2,6-diisopropylnaphthalene and 4,4'-diisopropylbiphenyl to the corresponding hydroperoxides with oxygen, at $60{ }^{\circ} \mathrm{C}$, in the presence of $N$-hydroxyphthalimide (NHPI) and AIBN have been performed. Process inhibition was observed at temperatures above $60{ }^{\circ} \mathrm{C}$ resulting in lower conversion. A favorable effect of electron-donating substituents (methoxy, phenyl) on the reaction rate were described. NHPI was separated from the cumene oxidation product and recycled 5 times. It has been demonstrated that oxygen can be replaced by air.
\end{abstract}

Keywords Oxidation - NHPI $\cdot$ Isopropylaromatic hydrocarbons $\cdot$ Hydroperoxides

\section{Introduction}

The industrial importance of the processes of selective oxidation of isopropyl aromatic hydrocarbons to hydroperoxides is mainly attributable to the fact that this process allows obtaining hydroxy aromatic compounds that may be useful as substrates in the synthesis of pharmaceuticals, pigments or polymers (Scheme 1) [1].

Currently, more than 7 million tons per year of phenol are obtained from cumene. In industrial systems, cumene is usually oxidized with air at $100-120{ }^{\circ} \mathrm{C}$ under

Electronic supplementary material The online version of this article (doi:

10.1007/s11144-013-0581-2) contains supplementary material, which is available to authorized users.

B. Orlińska $(\bowtie) \cdot$ J. Zawadiak

Department of Chemical Organic Technology and Petrochemistry, Silesian University of

Technology, Krzywoustego 4, 44-100 Gliwice, Poland

e-mail: beata.orlinska@polsl.pl 
Scheme 1 Phenols synthesis

via Hock's method

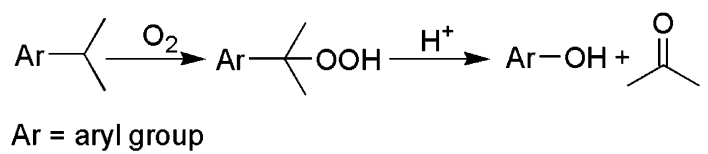

pressures of $0.5 \mathrm{MPa}$. The resulting product contains $20-30 \%$ of cumene hydroxyperoxide, which then undergoes acid-catalyzed decomposition to phenol [1-3]. This method is characterized by lower energy consumption and a smaller volume of waste compared to the classic sulfonation method, hence the ongoing studies on the implementation of Hock's method for the synthesis of other hydroxyaromatic compounds.

The oxidation processes of isopropylaromatic hydrocarbons to hydroperoxides, as recently shown, can be catalyzed by $N$-hydroxyphthalimide (NHPI) [4-11] as well as its derivatives [12]. Literature data concerning the NHPI-catalyzed oxidation of isopropylarenes are collected in Table 1.

The processes studied by Ishii et al. [6-8] were usually run at $75{ }^{\circ} \mathrm{C}$ using $10 \mathrm{~mol} \%$ of NHPI and $3 \mathrm{~mol} \%$ of 2,2'-azobis(2-methylpropionitrile) (AIBN) as the initiator. Among the studied solvents, the best results were obtained in MeCN [6, 7]. The reaction products (the hydroperoxide contents of which were not determined) were subjected to acid-catalyzed decomposition to hydroxyarenes. For example phenol from cumene was obtained in a maximum yield of $77 \%$ [6], whereas 2,6-dihydroxynaphthalene was obtained in $81 \%$ yield [8]. Recently, we have described the NHPI-catalyzed oxidations of isopropylarenes with a methoxy group in the aromatic ring, i.e., of 1-methoxy-4-(1-methylethyl)benzene (3) [9] and 2-methoxy-6-(1-methylethyl)naphthalene (5) [10] to hydroperoxides. The corresponding hydroperoxides were obtained in yields of 58 and $87 \%$ (conversion 60 and $92 \%$ ), respectively, when the processes were carried out at $60{ }^{\circ} \mathrm{C}$ in benzonitrile as a solvent. We have demonstrated that further temperature increase led to faster process inhibition resulted in lower hydrocarbons conversions and hydroperoxides yields.

Koshel' et al. [11] described the NHPI-catalyzed cumene oxidation reactions carried out without polar solvent at conditions similar to industrial process. At $120{ }^{\circ} \mathrm{C}$, in the presence of NHPI (2.7 wt $\%$ ) and AIBN, after $1 \mathrm{~h}$ of reaction, products containing 16.8 and $27.7 \%$ of cumene hydroperoxide were obtained using air and oxygen, respectively. The addition of NHPI increased the oxidation rate by a factor of 2.6 making possible the industrial process intensification without modification of technology.

Novikova et al. [12] compared the oxidation of cumene in the presence of NHPI and their derivatives: 4-tert-butyl- and 4-carboxyl- $N$-hydroxypthalimide, $N, N$ dihydroxypyromellitimide, $N$-acetoxyphthalimide and $N$-methoxyphthalimide. They observed that the catalytic activities of the studied catalyst decreased with the increase of the BDE values of the NO-H. The highest oxidation rate was obtained in the presence of 4-tert-butyl- $N$-hydroxypthalimide.

The combination of NHPI and aldehydes or variable valence metal salts has also been reported for oxidation of isopropylarenes. The hydroperoxide in cumene oxidation reaction catalyzed by $\mathrm{NHPI} / \mathrm{CH}_{3} \mathrm{CHO}$ system under moderate conditions at $25{ }^{\circ} \mathrm{C}$ was obtained with a yield of approximately $50 \%$ [13]. 


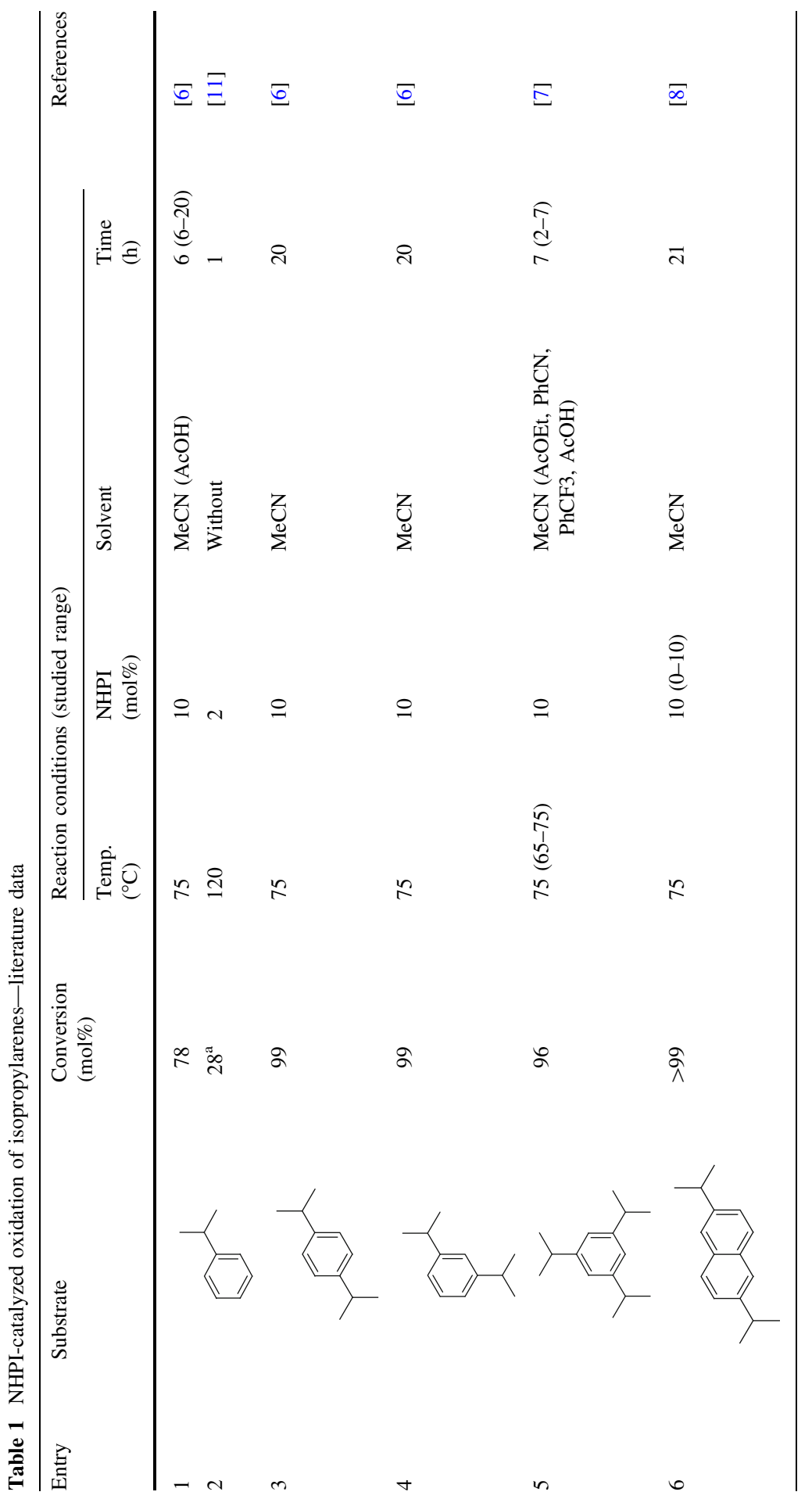




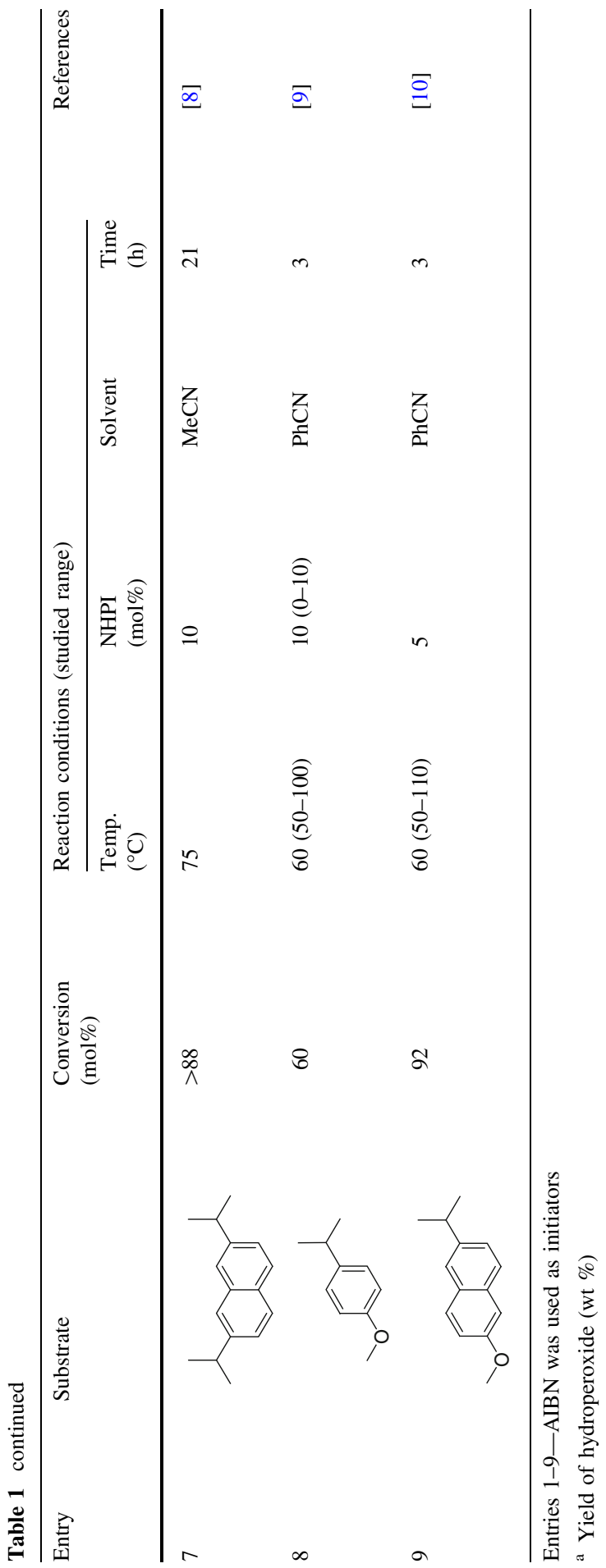


Scheme 2 Isopropylarenes 1-7<smiles>[R2]c1ccc(C(C)C)cc1</smiles>

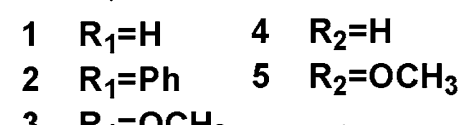

$3 \quad \mathbf{R}_{1}=\mathrm{OCH}_{3}$<smiles>C[R]=[R]OC</smiles>

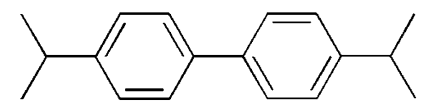

7

In contrast, the products of the oxidation of isopropylaromatic hydrocarbon catalyzed by NHPI and variable-valence metal salt systems primarily contained the corresponding alcohols and ketones [14-17]. The combination of NHPI and $\mathrm{Co}(\mathrm{OAc})_{2}$ in PEG-1000 based dication ionic liquid led even to formation of benzoic acid in the cumene oxidation reaction [18]. Therefore the processes are not useful for the synthesis of hydroperoxides.

In the present paper, the oxidation of selected mono- and diisopropylaromatic hydrocarbons 1-7, illustrated in Scheme 2, to hydroperoxides using NHPI as the catalyst are described. The choice of substrates was based on the potential capabilities of their oxidation processes to be used in the synthesis of valuable products-hydroxyarenes.

This study complements the papers published thus far on the oxidation of isopropylarenes in the presence of NHPI [6-12] with respect to the range of the influence of temperature and the electron-donating substituents (methoxy, phenyl) on the course of the reaction as well as catalyst recovery and air application. The oxidation of hydrocarbons $\mathbf{2 , 4}$ and $\mathbf{7}$ in the presence of NHPI to hydroperoxides are reported for the first time.

\section{Experimental}

Materials

Cumene (Merck) and 1-methoxy-4-(1-methylethyl)benzene (Lancaster Synthesis) were purified by distillation over sodium. 2-Isopropylnaphthalene was obtained by the crystallization of the technical product according to [19]. 2-Methoxy-6-(1- 
methylethyl)naphthalene was prepared from 2,6-diisopropylnaphthalene according to the procedure described in [10]. The other starting materials and catalyst were used without further purification.

Typical procedure

Isopropylaromatic hydrocarbon 1-7, NHPI, initiator (2,2'-azobis(2-methylpropionitrile) (AIBN) at $50-70{ }^{\circ} \mathrm{C}$ or $1,1^{\prime}$-azobis(cyclohexanecarbonitrile) (ACHN) at $90{ }^{\circ} \mathrm{C}$ ) and solvent $\left(\mathrm{MeCN}\right.$ at $50-70{ }^{\circ} \mathrm{C}$ or benzonitrile $(\mathrm{PhCN})$ at $\left.90{ }^{\circ} \mathrm{C}\right)$ were placed in a $25 \mathrm{ml}$ two-necked flask of a gasometric apparatus equipped with a magnetic stirrer $(1,000 \mathrm{rpm})$, a heating bath and a gas burette filled with oxygen under atmospheric pressure. The amount of consumed oxygen was measured over the course of the reaction and used to calculate hydrocarbon conversion (after recalculation to normal conditions- $273 \mathrm{~K}, 1 \mathrm{~atm}$.).

$$
\propto=\frac{n_{\mathrm{O}_{2}}}{n} \times 100 \%
$$

$\alpha$ conversion, $n_{\mathrm{O}_{2}}$ mmols of oxygen consumed at normal conditions, $n$ mmols of hydrocarbons 1-5 or isopropyl groups in case of hydrocarbons 6 and 7 .

The amount of hydroperoxides was iodometrically determined according to the described method [20], and the result was used for calculation of selectivity.

$$
S_{-\mathrm{OOH}}=\frac{n_{-\mathrm{OOH}}}{n_{\mathrm{O}_{2}}} \times 100 \%
$$

$S_{-O O H}$ hydroperoxides selectivity, $n_{-O O H}$ mmols of hydroperoxide groups based on iodometric analysis, $n_{\mathrm{O}_{2}}$ mmols of oxygen consumed at normal conditions.

The amounts of hydroperoxides $(6 \mathbf{a}, 6 \mathbf{b}, 7 \mathbf{a}$ and $7 \mathbf{b})$ in the oxidation products of 6 and 7 were determined by HPLC according to methods described in [21, 22] and used for calculation of yield and selectivity presented in Table 6 .

A Waters Alliance 2690 HPLC equipped with an autosampler, a UV detector (Waters photodiode array), and a Nova-Pak Silica $60 \AA 4 \mu \mathrm{m}$ column $(150 \mathrm{~mm} \times 3.9 \mathrm{~mm}$; Waters $)$ was used with a mixture of hexane and 2-propanol as the mobile phase (99:1-97:1 v/v).

The amounts of NHPI in the reaction mixture of the cumene oxidation process (conditions are given in Table 5, entry 5) were determined by HPLC using the above mentioned apparatus and detector and Merck LiChroCART 250-2 Purospher

Table 2 Effect of the amount of NHPI on the cumene oxidation process

Reaction conditions: $\mathrm{MeCN}-$ $10 \mathrm{ml}, \mathrm{AIBN}-3 \mathrm{~mol} \%, 60^{\circ} \mathrm{C}$, $3 \mathrm{~h}, 1,000 \mathrm{rpm}$

\begin{tabular}{lllll}
\hline Entry & $\begin{array}{l}\text { Cumene } \\
(\mathrm{mmol})\end{array}$ & $\begin{array}{l}\text { NHPI } \\
(\mathrm{mmol})\end{array}$ & $\begin{array}{l}\text { Conversion } \\
(\mathrm{mol} \%)\end{array}$ & $\begin{array}{l}\text { Selectivity } \\
(\mathrm{mol} \%)\end{array}$ \\
\hline 1 & 10 & 0 & 1.9 & 100 \\
2 & 10 & 0.1 & 28 & 100 \\
3 & 10 & 0.5 & 35 & 100 \\
4 & 10 & 1 & 46 & 100 \\
5 & 10 & 1.5 & 41 & 100 \\
6 & 20 & 2 & 22 & 100 \\
\hline
\end{tabular}


STAR RP-18e column and a mixture of $\mathrm{MeCN}$ and water as a mobile phase $(90: 10 \mathrm{v} / \mathrm{v}, 1 \mathrm{ml} / \mathrm{min})$. The amount of NHPI was compared in the samples taken after $5 \mathrm{~min}$ and $5 \mathrm{~h}$ of reaction. The presence of phenol in the cumene oxidation product were checked by GC MS analysis using Agilent 7890A chromatograph (HP5MS $30 \mathrm{~m} \times 0.25 \mathrm{~mm}$, helium $1 \mathrm{ml} / \mathrm{min}$, column temperature increased from 70 to $220{ }^{\circ} \mathrm{C}$ with a rate of $7{ }^{\circ} \mathrm{C} / \mathrm{min}$ ) combined with Agilent 5975I mass spectrometer with EI ionisation $(70 \mathrm{eV})$.

NHPI-catalyzed cumene oxidation in the presence of phthalic acid, phthalimide and phthalic anhydride

Cumene $(10 \mathrm{mmol})$, NHPI $(1 \mathrm{mmol}), \operatorname{AIBN}(0.3 \mathrm{mmol})$ and $\mathrm{PhCN}\left(10 \mathrm{~cm}^{3}\right)$ were placed in a $25 \mathrm{ml}$ two-necked flask of a described above gasometric apparatus and oxidized at $90{ }^{\circ} \mathrm{C}$ for $1 \mathrm{~h}$. Then additives were introduced; after $1 \mathrm{~h}$ phthalic acid $(0.05 \mathrm{mmol})$, after $2 \mathrm{~h}$ phthalimide $(0.05 \mathrm{mmol})$ and after $3 \mathrm{~h}$ phthalic anhydride $(0.05 \mathrm{mmol})$. The course of reaction was similar to that carried out without additives.

NHPI-catalyzed isopropylarenes oxidation using oxygen and air in a bubbler reactor

The oxidation was carried out in a $20 \mathrm{ml}$ glass reactor supplied with a bubbler, thermometer, reflux condenser and heating jacket. Hydrocarbon and MeCN were placed in the reactor and heated to the reaction temperature. After that, NHPI and AIBN were added, and the oxygen was passed through. During the process, samples were taken, and the content of hydroperoxide was determined iodometrically [20]. The amount of hydroperoxide was used for calculation of yields.

\section{Results and discussion}

The effect of reaction conditions

Within the initial studies, the influence of the amount of NHPI, temperature and solvent on the NHPI-catalyzed oxidation reaction of isopropylarenes was studied.

Table 2 provides a comparison of the cumene conversions obtained after $3 \mathrm{~h}$ of reaction conducted using $\mathrm{MeCN}$ as the solvent and different amounts of the catalyst.

The results showed that an increase in the NHPI amount in the range of $1-10 \mathrm{~mol} \%$ (entries $1-4$ ) led to an increase of cumene conversion, analogous to previous results reported by Ishii for 2,6-diisopropylnaphthalene [8]. Further increases in the amount of the catalyst are limited by its solubility in the system. With $15 \mathrm{~mol} \%$ of NHPI, the catalyst dissolved completely only after several dozen minutes (entry 5). The use of a higher concentration of the substrate (entry 6) decreased the solubility of NHPI in the system and left a substantial portion undissolved, which, in turn, resulted in a decreased in the cumene conversion. Subsequent studies were therefore performed using $10 \mathrm{~mol} \%$ of NHPI. 


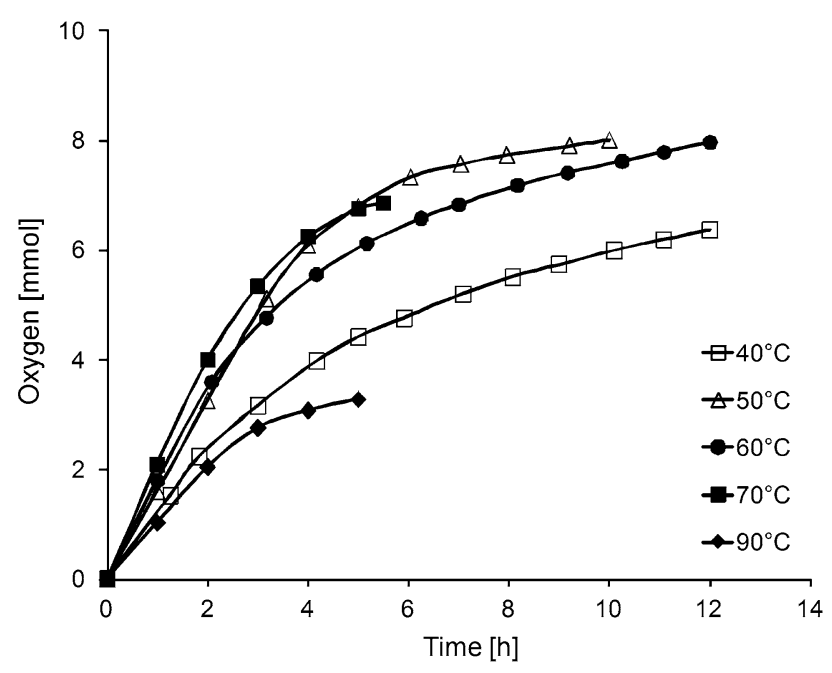

Fig. 1 Effect of temperature on cumene oxidation catalyzed by NHPI (reaction conditions are given in Table 3)

In this study, the effect of temperature in the range of $40-90{ }^{\circ} \mathrm{C}$ on the oxidation process of $\mathbf{1}$ and diisopropylarenes $\mathbf{6}$ and $\mathbf{7}$ was examined (Fig. 1; Table 3, Supplemental Fig. S3 and S4). The aim was to indicate that the previously observed decrease in the conversion rate at temperature greater than $60{ }^{\circ} \mathrm{C}$ in the case of the oxidation of $\mathbf{3}$ and $\mathbf{5}$, reported in our previous works [9,10], was not a result of the presence of methoxy group in the aromatic rings of $\mathbf{3}$ and $\mathbf{5}$.

Depending on the process temperature, different amounts of AIBN or ACHN were used as initiators, and the obtained initiation rates are also given in Table 3. An induction period of approx. $30 \mathrm{~min}$ was observed when compound 6 was oxidized at $40{ }^{\circ} \mathrm{C}$. To reduce the length of this induction period at 50 and $60{ }^{\circ} \mathrm{C}$, greater amounts of initiator were used in the case of the oxidation of 6 than in the oxidation processes of $\mathbf{1}$ and $\mathbf{7}$.

The obtained results showed that the highest conversions to hydroperoxides in the NHPI-catalyzed oxidation of compounds $\mathbf{1}, \mathbf{6}$ and $\mathbf{7}$ were obtained in the range of $50-60{ }^{\circ} \mathrm{C}$. A temperature increase above $60{ }^{\circ} \mathrm{C}$ led to a faster process inhibition resulting in lower conversion, analogously to previous results concerning the oxidation of hydrocarbons $\mathbf{3}$ and $\mathbf{5}[9,10]$.

The inhibition in the oxidation processes of isopropylaromatic hydrocarbons is usually related to the acid-catalyzed hydroperoxide decomposition to the corresponding phenols (even traces can retard the oxidation). Acids are known to be formed as a product of methyl-radical oxidation and methyl radicals are known to be formed in the $\beta$-scission reaction of 1-aryl-1-methylethyloxyl radicals [23].

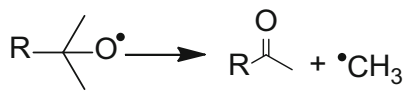


Table 3 Effect of temperature on isopropylaromatic oxidation catalyzed by NHPI

\begin{tabular}{lllllll}
\hline Entry & Substrate & $\begin{array}{l}\text { Temperature } \\
\left({ }^{\circ} \mathrm{C}\right)\end{array}$ & $\begin{array}{l}\text { Initiation rate }^{\mathrm{a}} \\
\left(\mathrm{mol} \mathrm{dm}^{-3} \mathrm{~s}^{-1}\right) \times 10^{6}\end{array}$ & $\begin{array}{l}\text { Time } \\
(\mathrm{h})\end{array}$ & $\begin{array}{l}\text { Conversion } \\
(\mathrm{mol} \%)\end{array}$ & $\begin{array}{l}\text { Selectivity } \\
(\mathrm{mol} \%)\end{array}$ \\
\hline 1 & 1 & 40 & 0.34 & 12 & 64 & 100 \\
2 & 1 & 50 & 0.34 & 10 & 80 & 100 \\
3 & 1 & 60 & 0.34 & 12 & 80 & 100 \\
4 & 1 & 70 & 1.19 & 5.5 & 69 & 100 \\
5 & 1 & 90 & 1.64 & 5 & 33 & 99 \\
6 & 6 & 40 & 0.32 & 14 & 52 & 100 \\
7 & 6 & 50 & 0.67 & 15 & 89 & 100 \\
8 & 6 & 60 & 1.19 & 12 & 80 & 100 \\
9 & 6 & 70 & 1.19 & 10 & 61 & 98 \\
10 & 6 & 90 & 1.64 & 5 & 19 & 95 \\
11 & 7 & 40 & 0.34 & 12 & 58 & 100 \\
12 & 7 & 50 & 0.34 & 12 & 77 & 100 \\
13 & 7 & 60 & 0.34 & 11 & 81 & 100 \\
14 & 7 & 70 & 1.19 & 8 & 51 & 97 \\
15 & 7 & 90 & 1.64 & 5 & 23 & 91 \\
\hline
\end{tabular}

Reaction condition: substrate $1-7-10 \mathrm{mmol}, \mathrm{MeCN}$ at $40-70{ }^{\circ} \mathrm{C}$ or $\mathrm{PhCN}$ at $90{ }^{\circ} \mathrm{C}-10 \mathrm{ml}$, NHPI$1 \mathrm{mmol}$, AIBN at $40-70{ }^{\circ} \mathrm{C}$ or $\mathrm{ACHN}$ at $90{ }^{\circ} \mathrm{C}, 1,000 \mathrm{rpm}$

${ }^{a}$ Rate of initiation was calculated using the equation $\mathrm{r}_{\mathrm{i}}=2 \mathrm{ek}_{\mathrm{d}} \mathrm{c}_{\mathrm{i}}$, where the coefficient of effectiveness $\mathrm{e}=0.6, \mathrm{k}_{\mathrm{d}}$ is the rate constant of thermal decomposition of AIBN or ACHN calculated based on data presented in [29-31] and $c_{i}$ is the concentration of the initiator

${ }^{\mathrm{b}}$ Conversion of diisopropylarenes 6 and 7 refer to the conversion of both isopropyl groups (20 mmol)

Furthermore, the decrease in the substrate conversion rate observed at $90{ }^{\circ} \mathrm{C}$ results from the change of the solvent from $\mathrm{MeCN}$ to $\mathrm{PhCN}$. The literature data indicate that the substitution of $\mathrm{MeCN}$ with $\mathrm{PhCN}$ results in a decrease in the substrate conversion in the case of triisopropylbenzene oxidation catalyzed by NHPI [7]. We have observed a similar effect (Table 4).

Initially, it was presumed that the conversion decrease at higher temperature could also be a result of NHPI decomposition. However, only a slight amount of NHPI was decomposed during the cumene oxidation process carried out at $90{ }^{\circ} \mathrm{C}$ (the NHPI amount decreased from 10 to $9 \mathrm{~mol} \%$; process conditions are given in Table 3, entry 5). It has been also demonstrated that phthalimide, phthalic anhydride

Table 4 Oxidation processes carried out in $\mathrm{MeCN}$ and $\mathrm{PhCN}$

\begin{tabular}{lllll}
\hline Entry & Substrate & Solvent & $\begin{array}{l}\text { Conversion } \\
(\mathrm{mol} \%)\end{array}$ & $\begin{array}{l}\text { Selectivity } \\
(\mathrm{mol} \%)\end{array}$ \\
\hline 1 & 1 & $\mathrm{PhCN}$ & 29 & 100 \\
2 & 1 & $\mathrm{MeCN}$ & 53 & 100 \\
3 & 6 & $\mathrm{PhCN}$ & 19 & 100 \\
4 & 6 & $\mathrm{MeCN}$ & 28 & 100 \\
\hline
\end{tabular}

Reaction conditions: substrate-10 mmol, solvent-10 ml, NHPI-1 mmol (10 mol\%), AIBN$0.3 \mathrm{mmol}$ ( $3 \mathrm{~mol} \%$ ), 1,000 rpm, $3 \mathrm{~h}, 70{ }^{\circ} \mathrm{C}$ 
and phthalic acid, known as a products of NHPI or PINO decomposition [5], had no negative influence the NHPI catalyzed cumene oxidation at $90{ }^{\circ} \mathrm{C}$.

Although GC MS analysis of cumene oxidation product obtained at $90{ }^{\circ} \mathrm{C}$ (reaction conditions are given in Table 3 entry 5) did not confirm the presence of phenol, its formation and negative impact on the process is still taken under the consideration. The formed phenol was probably consumed in subsequent reactions e.g. with free radicals and retarded the process.

\section{Oxidation processes of hydrocarbons 1-7}

Having established the conditions for the NHPI-catalyzed oxidation of isopropylarenes to the corresponding hydroperoxides $\left(50-60{ }^{\circ} \mathrm{C}, 10 \mathrm{~mol} \% \mathrm{NHPI}, \mathrm{MeCN}\right.$ as a solvent), we then examined the reaction for a wider range of substrate. Fig. 2 presents a comparison of the oxidation processes of compounds 1-7, whereas Table 5 lists the obtained conversions and hydroperoxide selectivities.

The results showed that the isopropylarenes 1-7 were oxidized to corresponding hydroperoxides with high conversions and selectivities. The yields of hydroperoxides obtained within the study are higher than those previously reported in literature. The reported lower yields obtained in the NHPI-catalyzed oxidation processes of 1,3 and 5 $[6,9,10]$ most likely result from the use of higher temperatures $\left(75^{\circ} \mathrm{C}\right)[6]$ or $\mathrm{PhCN}$ as the solvent $[9,10]$. Our research indicates that such conditions are less favorable.

The presented data indicate a favourable influence of methoxy and phenyl substituent in the aromatic ring of compounds $\mathbf{2}, \mathbf{3}$ and $\mathbf{5}$ on the NHPI-catalyzed oxidation process, resulted in an acceleration of the reaction rates. The presence of the electron-donating group in the aromatic ring most likely stabilizes the partial positive charge on the tertiary carbon atom in the transition state during the

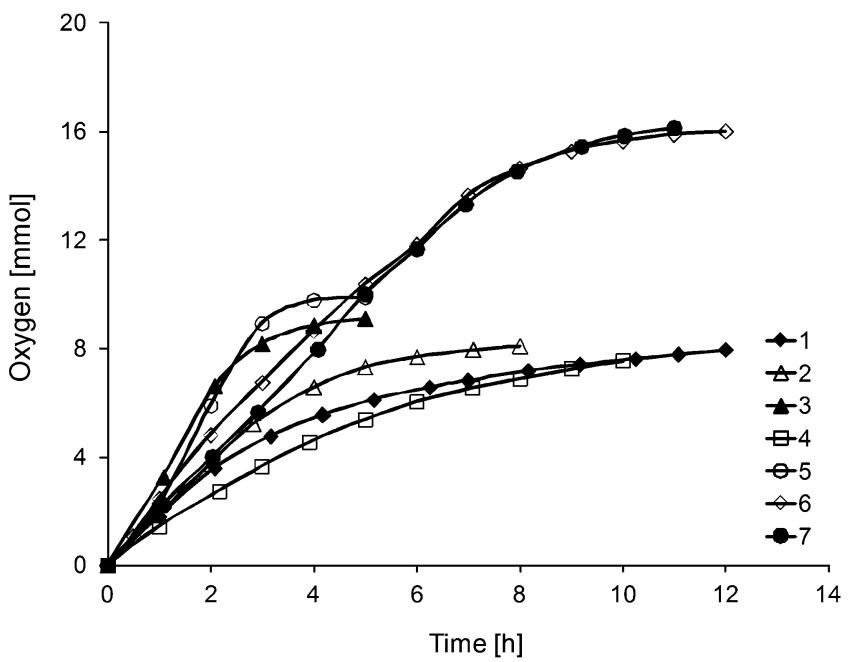

Fig. 2 Comparison of the oxidations of isopropylarenes 1-7 catalyzed by NHPI at $60{ }^{\circ} \mathrm{C}$ (reaction conditions are given in Table 5) 
Table 5 Conversion of hydrocarbons and selectivity of the hydroperoxides obtained in the oxidation processes catalyzed by NHPI

\begin{tabular}{|c|c|c|c|c|}
\hline Entry & Substrate & $\begin{array}{l}\text { Time } \\
\text { (h) }\end{array}$ & $\begin{array}{l}\text { Conversion } \\
(\mathrm{mol} \%)^{\mathrm{a}}\end{array}$ & $\begin{array}{l}\text { Selectivity } \\
(\mathrm{mol} \%)\end{array}$ \\
\hline 1 & & 12 & 80 & 100 \\
\hline 2 & & 8 & 80 & 100 \\
\hline 3 & & 5 & 91 & 100 \\
\hline 4 & & 10 & 76 & 100 \\
\hline 5 & & 5 & 99 & 100 \\
\hline 6 & & 12 & 80 & 100 \\
\hline 7 & & 11 & 81 & 100 \\
\hline
\end{tabular}

Reaction conditions: substrate 1-7-10 mmol, MeCN-10 ml, NHPI-1 mmol, AIBN was used in the amounts given in Table $3,60{ }^{\circ} \mathrm{C}, 1,000 \mathrm{rpm}$

${ }^{a}$ Conversion of diisopropylarenes 6 and 7 refer to the conversion of both isopropyl groups (20 mmol)

abstraction of the atom by the electrophilic PINO radical, which accelerates the propagation rate.<smiles></smiles> 
A similar influence of electron-donating substituents on the NHPI-catalyzed oxidation has been reported for toluene and ethylbenzene derivatives [24-26]. However, to the best of our knowledge, no such data are available for isopropylarenes.

\section{Oxidation processes of hydrocarbons 6 and 7 oxidation}

The studies showed that the products of the NHPI-catalyzed oxidation of compounds 6 and 7 contained only the corresponding mono- and dihydroperoxides (Table 6).

The analysis of the composition of the oxidation products of 6 and 7 revealed that it is possible to obtain the corresponding dihydroperoxides $\mathbf{6 b}$ and $\mathbf{7 b}$ in high yields and with high selectivities when the NHPI-catalyzed process is run at $50{ }^{\circ} \mathrm{C}$ for

Table 6 Yield and selectivity of the corresponding mono- and dihydroperoxides obtained from the oxidation of diisopropylarenes 6 and 7 in the presence of NHPI

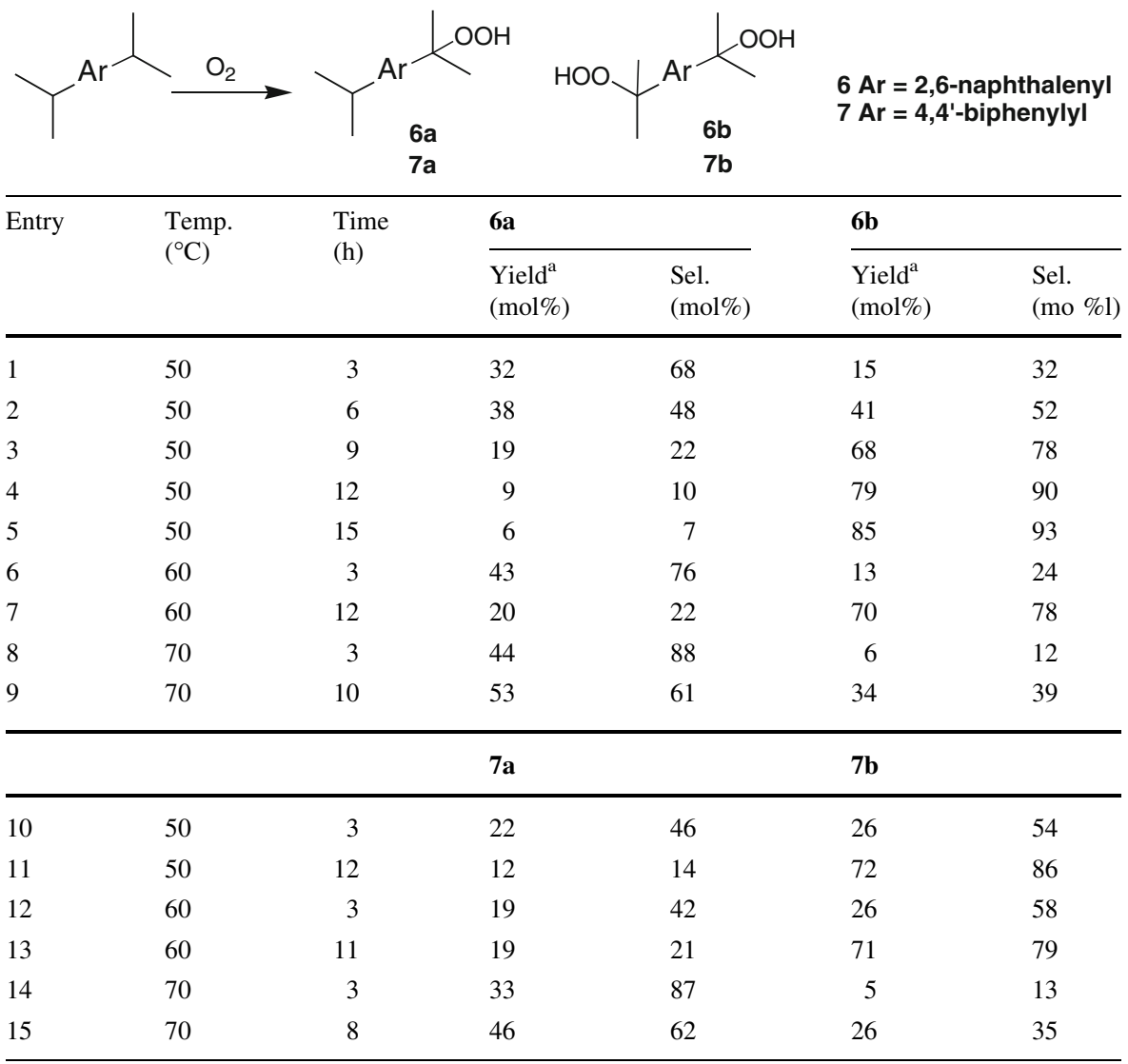

Reaction conditions: substrate 6 or $7-10 \mathrm{mmol}$, MeCN-10 ml, NHPI $-1 \mathrm{mmol}, 1,000 \mathrm{rpm}$, the amounts of AIBN used depends on the process temperature and are given in Table 3

a Yield was calculated based on HPLC determination of content of $6 \mathbf{a}, 6 \mathbf{b}, 7 \mathbf{a}$ and $7 \mathbf{b}$ 
Table 7 Cumene oxidation in the presence of recycled NHPI

\begin{tabular}{lllllll}
\hline Entry & Recycling & $\begin{array}{l}\text { Recycled NHPI } \\
(\mathrm{mmol})\end{array}$ & $\begin{array}{l}\text { Fresh NHPI } \\
(\mathrm{mmol})\end{array}$ & $\begin{array}{l}\text { Cumene } \\
(\mathrm{mmol})\end{array}$ & $\begin{array}{l}\text { Conversion } \\
(\mathrm{mol} \%)\end{array}$ & $\begin{array}{l}\text { Selectivity } \\
(\mathrm{mol} \%)\end{array}$ \\
\hline 1 & 0 & 0.0 & 1.0 & 10 & 61 & 100 \\
2 & 1 & 0.86 & 0.14 & 10 & 44 & 100 \\
3 & 2 & 0.80 & 0.20 & 10 & 65 & 100 \\
4 & 3 & 0.80 & 0.20 & 10 & 54 & 100 \\
5 & 4 & 0.86 & 0.14 & 10 & 57 & 100 \\
6 & 5 & 0.74 & 0.26 & 10 & 59 & 100 \\
7 & 0 & 0.0 & 0.0 & 10 & 64 & 100 \\
8 & 1 & 0.86 & 0.0 & 8.6 & 51 & 100 \\
9 & 2 & 0.61 & 0.0 & 6.1 & 57 & 100 \\
10 & 3 & 0.49 & 0.0 & 4.9 & 51 & 100 \\
11 & 4 & 0.40 & 0.0 & 4.0 & 50 & 100 \\
\hline
\end{tabular}

$\mathrm{MeCN}-10 \mathrm{ml}, \mathrm{AIBN}-0.3 \mathrm{mmol}, 5 \mathrm{~h}, 1,000 \mathrm{rpm}, 60^{\circ} \mathrm{C}$

12-15 h. It was also established that the corresponding monohydroperoxides 6a and 7a can be obtained with similarly high selectivities but in lower yields if the process is run at $70{ }^{\circ} \mathrm{C}$ for $3 \mathrm{~h}$.

Our previous studies described the methods of separation of the mixtures of mono- and dihydroperoxides obtained in the uncatalyzed oxidation of 6 and 7 [27, 28]. The oxidation of hydrocarbons $\mathbf{6}$ and $\mathbf{7}$ in the presence of NHPI, combined with the previously developed separation method based on differences in their acidity, are a promising approach to the synthesis of corresponding mono- and dihydroperoxides as intermediates for the synthesis of valuable mono- and dihydroxyarenes.

NHPI recovery and recycling

The studies on the catalyst separation and recycling were carried out for the process of cumene oxidation. After the process was completed, the $\mathrm{MeCN}$ was distilled off, and the NHPI was filtered and washing with hexane. The separated NHPI was used in the subsequent reaction with or without refilled of fresh catalyst.

The results presented in Table 7 showed that about $80 \%$ of NHPI was recovered by this method and can be recycled without meaningful loss in the hydroperoxide yield.

Cumene oxidation using air under atmospheric pressure

The processes of NHPI-catalyzed oxidation of cumene using oxygen and air were compared (Table 8 entries 1 and 2, Supplemental Fig. S5). The processes were carried out in a bubbler reactor under atmospheric pressure.

Although the rate of cumene oxidation using air was lower in the initial stages of the processes high yields of cumene hydroperoxide were obtained using both oxidizing agent. Therefore hydrocarbons 2-7 were also oxidized using air and 
Table 8 NHPI-catalyzed isopropylarenes oxidation using air and oxygen under atmospheric pressure

Reaction condition: substrate$20 \mathrm{mmol}, \mathrm{MeCN}-20 \mathrm{ml}$, NHPI-2 mmol, AIBN$0.61 \mathrm{mmol}$, gas flow$15 \mathrm{dm}^{3} / \mathrm{h}, 60^{\circ} \mathrm{C}, 8 \mathrm{~h}, 1 \mathrm{~atm}$.

\begin{tabular}{llll}
\hline Entry & Substrate & Oxidising agent & $\begin{array}{l}\text { Hydroperoxide yield } \\
(\mathrm{mol} \%)\end{array}$ \\
\hline 1 & 1 & Oxygen & 71 \\
2 & 1 & Air & 70 \\
3 & 2 & Air & 85 \\
4 & 3 & Air & 70 \\
5 & 4 & Air & 88 \\
6 & 5 & Air & 92 \\
7 & 6 & Air & 86 \\
8 & 7 & Air & 78 \\
\hline
\end{tabular}

respective hydroperoxides were obtained in high yields (Table 8, entries 3-8). The slight differences in hydroperoxides yields obtained using oxygen (Table 5) and air (Table 8) were probably the results of different process conditions (time of reaction, type of apparatus). Previously, the application of air in the NHPI-catalyzed isopropylarenes oxidation has been reported only in the papers $[8,11]$. However Ishii [8] oxidized hydrocarbon 6 using air under pressure of 20 atm., while Koshel' et al. [11] oxidized cumene under the conditions similar to the industrial process $\left(120{ }^{\circ} \mathrm{C}\right.$, without polar solvent, $\left.2.7 \% \mathrm{NHPI}\right)$ and obtained lower hydroperoxide yield in process with air than with oxygen (17 and $28 \mathrm{wt} \%$, resp. after $1 \mathrm{~h}$ of reaction).

\section{Conclusions}

- It has been shown that in order to obtain high yields of hydroperoxides, the oxidation reactions of the corresponding isopropylaromatic hydrocarbons with oxygen should be performed in the presence of $10 \mathrm{~mol} \%$ NHPI using MeCN as the solvent at temperature of $50-60{ }^{\circ} \mathrm{C}$. These results are in good agreement with previous works [6-10] and confirm that the reaction temperatures above $60{ }^{\circ} \mathrm{C}$ adversely affect the NHPI-catalyzed oxidation processes.

- The yields of hydroperoxides obtained within this study under the above mentioned conditions were higher than those previously reported in the literature $[6,9,10]$. The oxidation of hydrocarbons $\mathbf{1}, \mathbf{4}$ and $\mathbf{7}$ to hydroperoxides in the presence of NHPI was reported first time.

- The NHPI-catalyzed oxidation reactions of diisopropylarenes 6 and 7 to monoand dihydroperoxides, as described herein, in combination with the separation method that we have previously reported [27, 28], appears to be a promising approach to their synthesis as intermediates in the production of mono- and dihydroxyarenes.

- The favorable effect of electron-donating substituents (methoxy, phenyl groups) on the oxidation processes of isopropylarenes in the presence of NHPI was observed. 
- It has been demonstrated that NHPI can be easily separated from the product of cumene oxidation and used in subsequent reaction.

- It has been indicated for the first time that hydroperoxides could be obtained in high yields in the NHPI-catalyzed isopropylarenes 1-7 oxidation processes using air in place of oxygen under atmospheric pressure.

Acknowledgments Financial assistance from the National Science Centre of Poland (Grant No. N N209 153836) is gratefully acknowledged.

Open Access This article is distributed under the terms of the Creative Commons Attribution License which permits any use, distribution, and reproduction in any medium, provided the original author(s) and the source are credited.

\section{References}

1. Jordan W, van Barneveld H, Gerlich O, Kleine-Boymann M, Ullrich J (1991) In: Elvers B, Hawkins S, Schulz G (eds) Ullmann's encyclopedia of industrial chemistry, vol A19. VCH GmbH, Weinheim, p 299

2. Meyers RA (2005) Handbook of petrochemicals production processes. McGraw-Hill, New York, p 9.8

3. Schmidt RJ (2005) Appl Catal A Gen 280:89

4. Ishii Y, Sakaguchi S (2004) In: Bäckvall J-E (ed) Modern oxidation methods. Wiley-VCH, Weinheim, p 132

5. Recupero F, Punta C (2007) Chem Rev 107:3800

6. Fukuda O, Sakaguchi S, Ishii Y (2001) Adv Synth Catal 343:809

7. Aoki Y, Hirai N, Sakaguchi S, Ishii Y (2005) Tetrahedron 61:10995

8. Aoki Y, Sakaguchi S, Ishii Y (2004) Adv Synth Catal 346:199

9. Orlińska B, Romanowska I (2011) Cent Eur J Chem 9:670

10. Orlińska B, Stec Z, Zawadiak J (2012) Monatsh Chem 143:295

11. Koshel' GN, Smirnova EV, Kurganova EA, Rumyantseva YuB, Plakhtinskii VV, Koshel' SG (2012) Catal Ind 4:96

12. Novikova KV, Kompanets MO, Kushch OV, Kobzev SP, Khliestov MM, Opeida IO (2011) Reac Kinet Mech Cat 103:31

13. Melone L, Gambarotti C, Prosperini S, Pastori N, Rescupero F, Punta C (2011) Adv Synth Catal 353:147

14. Minisci F, Recupero F, Cecchetto A, Gambarotti C, Punta C, Paganelli R (2004) Org Process Res Dev 8:163

15. Minisci F, Punta C, Recupero F (2006) J Mol Catal A: Chem 251:129

16. Nakamura R, Obora Y, Ishii Y (2009) Tetrahedron 65:3577

17. Orlińska B (2010) Tetrahedron Lett 51:4100

18. Lu T, Lu M, Yu W, Liu Z (2012) Croat Chem Acta 85:277

19. Takahashi M, Yamauchi T, Imura T British Patent 1496227 (1977) Kureha Kagaku Kogyo kk

20. Zawadiak J, Gilner D, Kulicki Z, Baj S (1993) Analyst 118:1081

21. Zawadiak J, Orlińska B, Stec Z (2000) Fresenius J Anal Chem 367:502

22. Orlińska B, Stec Z, Zawadiak J, Hefczyc B (2007) Chem Anal (Warsaw) 52:689

23. Denisov ET, Afanas'ev IB (2005) Oxidation and antioxidants in organic chemistry and biology. Taylor \& Francis Group, Boca Raton

24. Coseri S (2009) Catal Rev 51:218

25. Ishii Y, Sakaguchi S, Iwahama T (2001) Adv Synth Catal 343:393

26. Melone L, Prosperini S, Gambarotti C, Pastori N, Rescupero F, Punta C (2012) J Mol Catal A: Chem $355: 155$ 
27. Stec Z, Zawadiak J (1998) Pol J Appl Chem 42:237

28. Stec Z, Zawadiak J, Zellerhoff R, Orlińska B (2003) Przem Chem 82:637

29. Overberger CG, Biletch H, Finestone AB, Lilker J, Herber J (1953) J Am Chem Soc 75:2078

30. Van Hook JP, Tobolsky AV (1958) J Am Chem Soc 80:779

31. Russel GA (1975) J Am Chem Soc 79:3871 